\title{
A emergência da microconstrução considerando que na rede dos conectivos condicionais
}

\section{The emergence of the microconstruction considerando que on the network of the conditional connectives}

\author{
Duílio Fabbri Júnior ${ }^{1}$ \\ Camila Gabriele da Cruz Clemente ${ }^{2}$
}

Resumo: Nos séculos XIX e XX, encontramos a microconstrução "considerando que" como conectivo condicional. Como hipótese, acreditamos que "considerando que" passou por um processo semelhante ao conectivo "supondo que", uma vez que ambos partem da categoria dos verbos cognitivos e passam a integrar um dos subesquemas da rede dos conectivos condicionais, o subesquema [V_que], com novas formas e nova função (a condicional). Assim, também propomos que se trata de um caso de construcionalização. Como objetivo principal, pretendemos apresentar os micropassos de mudanças construcionais e a construcionalização do conectivo condicional "considerando que" (verbo + "que"). Para tanto, utilizamos especialmente a teoria da mudança linguística de Traugott e Trousdale (2013). Também nos amparamos em Dancygier (1998) e Dancygier e Sweetser (2005) em relação aos parâmetros da condicionalidade, e, ainda, nos estudos acerca dessa categoria pelo viés da abordagem construcional de Oliveira (2019a; 2019b). No total, foram encontradas 11 ocorrências, nos séculos XIX e XX, no Corpus do Português, em que "considerando que" atua como conectivo condicional.

Palavras-chave: Mudança construcional. Construcionalização. Construções condicionais. Conectivos condicionais.

\begin{abstract}
In the 19th and 20th centuries, we found the microconstruction "considerando que" as a conditional connective. Our hypothesis is that "considerando que" went through a process similar to the connective "supondo que", since both start from the category of cognitive verbs and later, start to integrate one of the subschemas of the conditional connective network, the subschema [V_que], with new forms and a new function (the conditional). Thus, we believe this is a case of constructionalization. The main objective is to present the micro-steps of construction changes and the constructionalization of the conditional connective "considerando que" (verb + "que"). Due to it, we followed after Traugott and Trousdale's (2013) theory of linguistic change. We also used Dancygier (1998) and Dancygier and Sweetser (2005) to check the parameters of conditionality, and Oliveira's constructional studies $(2019 \mathrm{a} ; 2019 \mathrm{~b})$ about this category. In total, 11 occurrences were found, in the 19th and 20th centuries, in Corpus do Português, in which "considerando que" works as a conditional connective.
\end{abstract}

Keywords: Constructional change. Constructionalization. Conditional constructions. Conditional connectives.

1 Centro Universitário Salesiano de São Paulo, Americana, SP, Brasil. Endereço eletrônico: juniorduilio@uol.com.br.

${ }^{2}$ Universidade Federal de São Carlos, Programa de Pós-Graduação em Estudos Linguísticos, São Carlos, SP, Brasil. Endereço eletrônico: camila_gabrieletl@ hotmail.com. 


\section{Introdução}

Há muito tempo, estudiosos dedicam atenção à formação de conectivos nas línguas. Já no trabalho de Meillet (1912), em relação ao processo de mudança do advérbio magis, do latim, à origem da conjunção adversativa "mas" no português, pelo viés da Gramaticalização, notamos que palavras de ligação, como os conectivos, sempre estiverem em processo de mudança. Atualmente, esse interesse ainda persiste entre os estudos da linguagem. Trabalhos mais recentes, como o de Moreira e Bispo (2017), sobre a expressão "na hora (em) que", e de Oliveira (2019a), sobre o "supondo que", nos mostram que conectivos emergem na língua a partir de construções já existentes.

De acordo com Longhin-Thomazi (2004, p.140), a combinação da partícula "que" com palavras de diferentes categorias é um processo produtivo e antigo no português. O subesquema [V_que], por exemplo, permite ao usuário da língua uma gama de possibilidades de preenchimento. Uma dessas possibilidades é a forma "considerando que", objeto de estudo deste trabalho, composto a partir do verbo "considerar", na forma gerúndio, mais a conjunção "que". Ambas as construções ${ }^{3}$ já existiam na língua, mas passaram também a ser utilizadas juntas, como um chunk $^{4}$, para elaborar sentido condicional.

Em relação à categoria condicional, essa é uma categoria com extrema complexidade, pois "os elementos usados para marcar a construção condicional apresentam graus de gramaticalização variados" devido "à natureza não discreta da categoria" e "aos diferentes padrões sintáticos sancionados pelo sistema condicional” (OLIVEIRA, 2019b, p. 6). Nesse sentido, vemos que a descrição da trajetória de mudança dessa categoria nos permite um entendimento da linguagem e sua dinamicidade. Mais especificamente, pretendemos contribuir para a descrição dos processos de mudança da língua a partir da categoria condicional, pela visão da abordagem construcional, que defende dois tipos de mudança: mudanças construcionais e construcionalização.

Para tanto, organizamos o artigo da seguinte maneira: nas duas próximas seções, apontamos e descrevemos alguns fundamentos teóricos sobre a teoria da mudança linguística com base em Traugott e Trousdale (2013), que seguem a abordagem construcional de língua, e sobre a categoria condicional, com autores como Dancygier (1998), Dancygier e Sweetser (2005) e Oliveira (2019a; 2019b), que propõem a interpretação da condicionalidade por

\footnotetext{
${ }^{3}$ Conforme Traugott e Trousdale (2013), construções são pareamentos de forma e significado. São tidas por autores como Traugott e Trousdale (2013) e Rosário e Oliveira (2016) como as unidades básicas da língua.

${ }^{4} \mathrm{O}$ processo de criar chunks é denominado chunking. Bybee (2010) e Traugott e Trousdale (2013) defendem que o uso, sempre em mesma ordem, de sequências linguísticas desencadeia o chunking. Em outras palavras, os usuários da língua repetem tanto determinadas sequências de construções que essas passam a ter um valor em conjunto, e não mais das partes.
} 
aspectos da forma e do significado. Em seguida, mostramos a metodologia desta pesquisa, ou seja, os parâmetros de análise e como esta foi conduzida para, então, realizarmos a análise dos dados. Por fim, as "Considerações finais", com os resultados encontrados, seguidas das "Referências".

\section{A teoria de Traugott e Trousdale (2013)}

Nesse trabalho, assumimos a teoria da mudança linguística de Traugott e Trousdale (2013), que consideram a língua enquanto um sistema de construções, unidades linguísticas básicas, organizadas em redes construcionais interligadas, como mostra a figura 1:

Figura 1 - Rede de construções

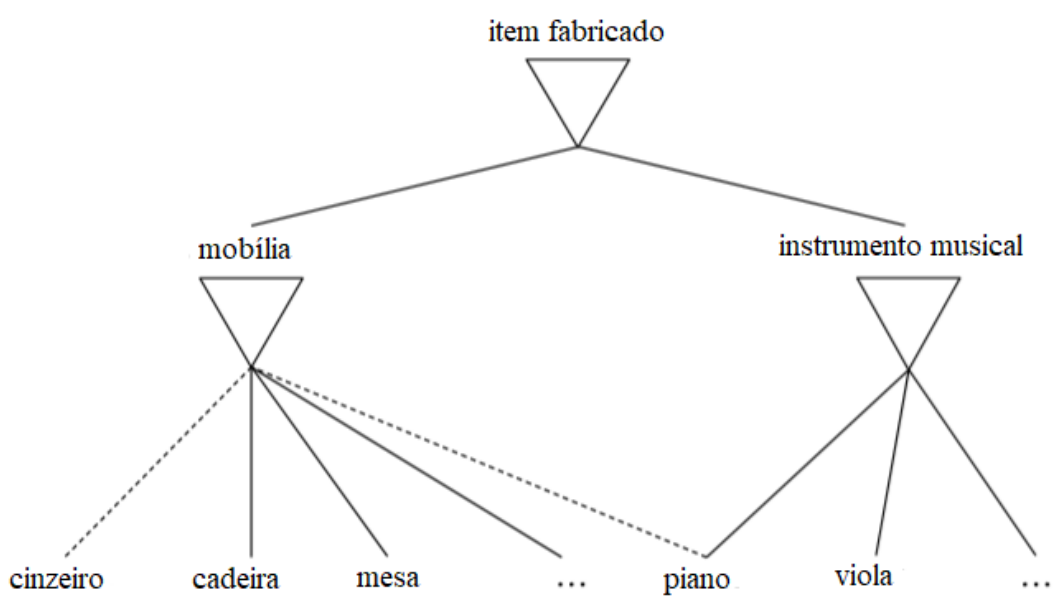

Fonte: Adaptado de Traugott e Trousdale (2013, p. 10)

Como mostra a figura 1, o item 'piano', embora seja melhor representante da categoria “instrumento musical" (representado pela linha contínua), também possui características de mobília (menos representativo, representado pela linha tracejada). Assim, "piano" integra tanto a rede construcional de "mobília", como a de "instrumento musical" ao mesmo tempo, por questão de herança múltipla. Portanto, os pesquisadores que se baseiam nessa abordagem não se dedicam apenas a itens individuais, pois, como já mencionado, cada item está interconectado. Há um olhar sobre o item em relação a um todo.

Para a abordagem construcional, todo o conhecimento que o usuário da língua possui sobre ela é considerado conhecimento sobre construções. Isso ocorre, pois Traugott e Trousdale (2013) definem "construção" como todo pareamento linguístico de forma e significado. Logo, não há distinção, e muito menos discriminação, quanto a itens gramaticais e lexicais. Ambos são estudados pelas Gramáticas de Construções. Para melhor 
compreendermos o que seriam as construções, na figura 2, abaixo, colocamos a proposta de Croft (2001, p.18), traduzida por Rosário e Oliveira (2016, p. 240).

Figura 2 - A estrutura da construção

\begin{tabular}{|c|}
\hline C O N S T R U Ç Ã O \\
\hline Propriedades sintáticas \\
Propriedades morfológicas FORMA \\
Propriedades fonológicas \\
$\uparrow$ \\
ELO DE CORRESPONDÊNCIA SIMBÓLICA \\
$\downarrow$ \\
Propriedades semânticas \\
Propriedades pragmáticas SENTIDO \\
Propriedades discursivo-funcionais \\
\hline
\end{tabular}

Fonte: Rosário e Oliveira (2016, p. 240)

Na figura 2 vemos que uma construção se estrutura pelo elo de correspondência simbólica de forma e de significado: a forma é composta por propriedades sintáticas, morfológicas e fonológicas; e o significado, por propriedades semânticas, pragmáticas e discursivo-funcionais. A construção, então, pode ser representada por $[[\mathrm{F}] \leftrightarrow[\mathrm{S}]]^{5}$ (TRAUGOTT; TROUSDALE, 2013), sendo "F" para forma e "S" para significado.

Em relação às redes, as construções se encontram em diferentes níveis construcionais (Figura 3). O nível mais geral e abstrato, denominado esquema, ou então, em um nível intermediário, subesquema, e por fim, um nível mais específico, microconstrução. Entretanto, tais posições não são estáticas, pois a língua é um sistema dinâmico, que se adapta às necessidades de seus usuários. Em outras palavras, as redes construcionais estão em constante mudança devido às pressões de uso.

\footnotetext{
${ }^{5}[[\mathrm{~F}] \leftrightarrow[\mathrm{M}]]$ construction (whether micro- or schema level) (TRAUGOTT; TROUSDALE, 2013). "F" para form e "M" para meaning.
} 
Figura 3 - Níveis hierárquicos das construções conforme Traugott e Trousdale (2013)

\section{Esquema}

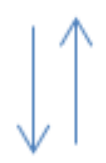

\section{Subesquema}

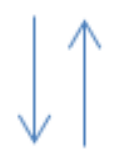

\section{Microconstrução}

Fonte: Elaboração própria.

Para aferir as mudanças linguísticas, Traugott e Trousdale (2013) propõem observar os graus de esquematicidade, produtividade e composicionalidade das construções. Segundo Traugott e Trousdale (2013), geralmente as mudanças são acompanhadas de aumento na produtividade e na esquematicidade, e diminuição na composicionalidade.

No tocante à produtividade, uma construção é considerada produtiva quando apresenta alta frequência type ou/e token - frequência de tipo e frequência de ocorrência, respectivamente, conforme Rosário e Oliveira (2016, p. 245). O número dos diferentes exemplares de uma construção corresponde a sua frequência tipo, enquanto a frequência token refere-se ao número de vezes que os types aparecem no uso da língua. "Considerando que", por exemplo, apresenta apenas uma frequência type: [considerando_que [oração finita]]. Ou ainda, "considerando que" é um dos types do subesquema [V_que], assim como "supondo que", "dado que" etc., propostos por Oliveira (2019b). Em relação à frequência token, "considerando que" foi utilizada com valor condicional em apenas 11 ocorrências ${ }^{6}$, ou seja, se realizou em um número de 11 tokens no corpus analisado, um número que corresponde à baixa frequência token. Assim, podemos dizer que "considerando que" é uma construção com baixa produtividade na rede dos conectivos condicionais nos séculos XIX e XX.

Para descrever o grau de esquematicidade das construções, além dos níveis construcionais serem marcados por diferentes graus de esquematicidade (esquema, subesquema e microconstrução), é possível observar também esse parâmetro no preenchimento do slot, ou seja, na própria forma da construção. Quanto menos esquemática uma construção, menos possibilidades de preenchimento de slot ela possui. Por exemplo, a expressão idiomática "acabar em pizza", com sentido de "permanecer tudo do jeito que está",

\footnotetext{
${ }^{6}$ Das 201 ocorrências do Corpus do Português, apenas 11 apresentam valor condicional nos séculos XIX e XX e, portanto, foram coletadas.
} 
possui seu slot totalmente preenchido, sem possibilidade de alteração de suas partes (não podemos dizer "acabar em sopa" ou "acabar em lanche", pois não terá o mesmo significado na língua), é considerada uma construção menos esquemática. Assim também ocorre com a construção "considerando que", nosso objeto de investigação, que possui apenas a possibilidade de preenchimento do verbo "considerar" na forma gerúndio "considerando" + a conjunção “que”, e então, é considerada uma construção menos esquemática.

Em contrapartida, em um nível totalmente esquemático, há construções que possuem todas as suas partes com possibilidade de preenchimento, como [SNloc], que pode ser "uma menina lá”, “o negócio lá”, "o carro ali” etc, e assim, é considerada uma construção altamente esquemática. Há também um nível intermediário de esquematicidade, como a construção [Xmente], que é mais ou menos esquemática, pois possui uma parte alterável "X", que pode ser preenchida por um adjetivo, e por uma parte fixa "mente", formando construções como “desesperadamente", "rapidamente" etc.

No quesito composicionalidade, Traugott e Trousdale (2013, p. 19) afirmam que essa pode ser pensada tanto no âmbito semântico, como no sintático. Isto é, uma construção é considerada mais composicional quando possui características semânticas e/ou sintáticas de suas partes, enquanto em uma menos composicional, a semântica e/ou a sintaxe de suas partes não correspondem com sua totalidade. Em suma, podemos dizer que a composicionalidade varia de acordo com o grau de relação entre forma e significado. Rosário e Oliveira (2016, p.246) classificam os conectivos "todavia" e "embora" como construções menos composicionais, uma vez que já não se consegue verificar seus aspectos originários.

Traugott e Trousdale (2013) explanam sobre dois tipos de mudança: i) mudança construcional, quando ocorrem mudanças em construções já existentes, em apenas um plano: ou da forma ou do significado; ii) construcionalização, que resulta na emergência de uma nova construção, pois afeta, concomitantemente, propriedades semânticas e formais das construções. Em ambos os processos estão envolvidos neoanálise ${ }^{7}$, isto é, novas interpretações ou associações contextuais (BYBEE, 2010), e/ou analogização, quando o usuário da língua cria uma nova construção espelhada em outra já existente. Esses processos serão mostrados na seção de análise dos dados, mais adiante, no decorrer do texto.

\footnotetext{
${ }^{7}$ De acordo com Traugott e Trousdale (2013), o usuário da língua cria novos pareamentos de forma e/ou de significados a partir da neoanálise de construções já existentes.
} 


\section{As construções condicionais}

De acordo com Dancygier (1998), as construções condicionais são compostas por uma oração condicionante, também chamada prótase, e uma oração condicionada, também chamada de apódose, representadas pela estrutura sintática “se p, q” (DANCYGIER, 1998).

Embora o conectivo se seja o núcleo prototípico da categoria, Neves (2000) e Oliveira (2009; 2014; 2019b) mostram que é possível que a categoria condicional seja expressa por uma grande variedade de conectivos, tais como, "supondo que", "desde que", "dado que", "somente se", "salvo se", "exceto se", “a menos que", "sem que", "uma vez que", "caso", entre outros, alguns listados no quadro (1) abaixo.

Quadro 1 - Subesquemas e microconstruções condicionais

\begin{tabular}{|l|l|}
\hline \multicolumn{1}{|c|}{ Subesquemas } & \multicolumn{1}{c|}{ Microconstruções } \\
\hline [V que $]$ & dado que, posto que, supondo que, considerando que \\
\hline [ADV que] & contanto que \\
\hline [PREP que $]$ & desde que, sem que \\
\hline [ADV se $]$ & somente se, exceto se, só se \\
\hline [PREP N PREP] & no caso de \\
\hline [PREP N PREP que $]$ & na condição de que, na eventualidade de que \\
\hline [PREP NEG COP que $]$ & a não ser que \\
\hline [PREP ADV que] & a menos que \\
\hline
\end{tabular}

Fonte: Adaptado de Oliveira (2019b, p. 15).

No quadro (1) acima se encontram apenas alguns dos subesquemas instanciados pelo esquema condicional, altamente produtivo na língua, já que sanciona um alto número de construções hierarquicamente inferiores, como algumas exemplificações vistas no quadro (1), e, ainda outros que não foram apontados. Oliveira (2019b) apresenta o slot a seguir como representação do esquema condicional:

\section{[[CON] ORAÇÃOj] [condição] ${ }^{8}$}

Ao considerar os níveis hierárquicos das redes construcionais, temos a construção acima no mais alto nível esquemático e abstrato da língua, pois essa pode ser preenchida de

8 “[[CON] ORAÇÃOj] refere-se a forma da construção condicional e [condição] representa, de modo mais esquemático, o significado condicional” (OLIVEIRA, 2019, p. 15); e “j” é a variável para se referir a oração. 
várias formas e sanciona uma vasta variedade de construções nos níveis de subesquemas e microconstruções.

Segundo Oliveira (2019b), todas as construções listadas no quadro (1) podem trabalhar no estabelecimento da condicionalidade, de alguma maneira. Alguns deles contribuem mais para os traços condicionais, enquanto outros necessitam recorrer à ajuda de aspectos pragmáticos.

Dancygier (1998) propõe os seguintes parâmetros para que se reconheçam as construções condicionais em qualquer língua. Com eles, vemos que o significado condicional não depende exclusivamente de um único elemento. Ele é a soma das cinco contribuições em conjunto, o que o caracteriza como pareamento de forma e significado, consoante à teoria de Traugott e Trousdale (2013). Vejamos:

1) Causalidade: diz respeito à relação de causalidade não preenchida existente entre p e q, que pode ser interpretada em quatro domínios cognitivos distintos, sendo esses, o de conteúdo, o epistêmico, o ato de fala e o metatextual (DANCYGIER; SWEETESER, 2005). Desses, temos a maior percepção de causa no domínio de conteúdo, e o domínio mais intersubjetivo, o metatextual, com causalidade quase que imperceptível.

2) Não assertividade: de acordo com Dancygier (1998), a não assertividade é um traço básico das condicionais, pois toda construção condicional apresenta suposições, que não podem ser tidas como reais. Portanto, seu conteúdo será sempre não assertivo.

3) Predição: a capacidade das construções condicionais de criar situações hipotéticas em um tempo futuro.

4) Postura epistêmica: nas condicionais, o usuário da língua faz uma dissociação mental em relação à informação da prótase, podendo assumir, assim, postura epistêmica neutra, quando não demonstra crença nem descrença, ou negativa, quando sinaliza acreditar na impossibilidade da proposição. Em ambas as posturas, notamos um distanciamento do usuário da língua perante o enunciado.

5) Espaços mentais: as construções condicionais funcionam como criadoras de espaços mentais hipotéticos, distintos do espaço realidade. Ao observar a estrutura "se p, q", 
temos que "p" é um espaço temporário criado para validar "q", e "q" é o espaço mental criado a partir de "q".

A partir desses parâmetros podemos verificar se "considerando que" integra a rede dos conectivos condicionais e qual seu grau de pertencimento à categoria, pois conforme Oliveira (2019, p. 375), "quanto mais o significado depender de aspectos contextuais, mais periférica e distante do núcleo prototípico será a construção". Isto é, quanto mais a construção "considerando que" recorrer ao contexto para estabelecer condicionalidade, mais distante do núcleo da categoria condicional estará.

\section{Metodologia}

Primeiramente, fizemos acesso na aba "Género / Histórico" Corpus do Português (DAVIES; FERREIRA, 2006), composto por mais de 45 milhões de palavras de textos falados e escritos, com a possibilidade de busca de dados pelas variedades do Português Brasileiro ou Europeu, pelos séculos XIV ao XX, pelo tipo textual, além de apontar a frequência de uso.

No campo de busca, buscamos por "considerando que". Das 201 ocorrências, foram encontradas apenas 11 ocorrências nos seguintes critérios: i) possuir o conectivo “considerando que", ii) apresentar os parâmetros da condicionalidade de Dancygier (1998), iii) ter ocorrido no século XIX ou $\mathrm{XX}^{9}$.

Após a coleta, verificamos se os micropassos de mudanças expostos em Oliveira (2019a) também ocorriam com a construção "considerando que", pois como já dito, nossa hipótese é de que "considerando que" sofreu neoanálise por analogização ao "supondo que".

Para confirmar sua condicionalidade, utilizamos os parâmetros de Dancygier (1998) — não assertividade, causalidade, predição, espaços mentais e postura epistêmica. Por fỉm, iniciamos a descrição do processo de emergência da microconstrução "considerando que" na rede dos conectivos condicionais.

\section{O surgimento da microconstrução considerando que na rede dos conectivos condicionais}

Primeiramente, para entendermos o conectivo "considerando que", vemos que esse é composto por um verbo cognitivo, "considerar", com valor semântico de "levar algo em conta/ considerar algo como possível”, conforme vemos a seguir:

\footnotetext{
9 Apenas a partir do século XIX que a microconstrução "considerando que" passa a integrar a rede dos conectivos condicionais.
} 
(1) As autoridades da Flórida Eua estão considerando medidas para dificultar a obtenção de licença para dirigir por adolescentes de 16 anos. Um estudo mostrou que os motoristas de 16 anos são o grupo mais perigoso em as ruas. (19N:Br:Folha)

Na ocorrência acima, vemos que "considerar" relaciona-se com o sujeito da oração principal, "as autoridades da Flórida Eua”. São elas que estão considerando algo, nesse caso, "as medidas para dificultar a obtenção de licença para dirigir por adolescentes de 16 anos". Desse modo, temos ainda propriedades verbais: "considerando" como uma forma conjugada do verbo "considerar".

Porém, no caso (2), temos uma tênue mudança na semântica de "considerar", utilizado com um valor modal, muito próximo de verbos como "crer" e "acreditar":

(2) Mesmo assim manteve-se inabalável, considerando ser a sua atitude a única viável. (19Ac:Pt:Enc)

Nesse caso, "considerando" é utilizado com uma forma não finita, "ser", o que demonstra que ainda possui aspectos da categoria verbal, mas, se distancia um pouco de seu sentido original. Em (2), o "considerando ser a sua atitude a única viável" atua como uma crença do sujeito da oração. Abaixo, em (3), vemos que "considerando" também é utilizado para denotar o julgamento de um sujeito, entretanto, não mais um sujeito gramatical:

(3) Este é um projeto de desenvolvimento entre o Estado e o BID, que veio de antes do Governo Arraes, mas que ele deu prosseguimento. Na realidade, o projeto é fruto de workshops realizados entre trabalhadores, empresários e os governos do Estado e Federal, coordenado pelo Ministério da Fazenda. Agora está em fase de negociação e acredito que começa a ser implantado a partir de 98. São R 240 milhões. Trata-se de um programa interessante. É lamentável que seja apenas para a Zona da Mata. Mas, considerando que maior miséria está mesmo nesta região, sem dúvida não se pode dizer que este não é um passo importante. (19Or:Br:Intrv:Com)

$\mathrm{Na}$ ocorrência (3), vemos que o usuário da língua insere seu julgamento no discurso: ser considerada a região de maior miséria é uma crença do usuário da língua. Não há mais um sujeito gramatical que concorda com a conjugação "considerando que", pois o sujeito passa a 
ser o enunciador que marca sua posição ${ }^{10}$ perante o evento descrito: negativa, geralmente marcada pelo emprego do pretérito, ou neutra, como visto em (3) com o uso do presente "está".

A partir daí, podemos dizer que "considerando que" começa a funcionar como conectivo condicional. Além da perda do sujeito gramatical, "considerando que" também desempenha papel de modificação entre as duas construções: toda a informação introduzida por ele passa a ser lida como não factual, que é crucial para sua reanálise enquanto conectivo condicional. Como há uma relação de dependência entre as duas construções, ambas são tidas como não factuais. Verifica-se, então, que "considerando que" atua como marcador de não assertividade, outro aspecto da categoria condicional.

Além da marcação de não assertividade, é possível perceber outro traço condicional em "considerando que": a capacidade de predição, ou seja, a capacidade que a condicional tem de fazer uma possível previsão futura sobre algo relacionado à construção matriz, como ocorre em (4):

(4) Considerando que o nicho ecológico de uma espécie, ou seja, a sua identidade ecológica (como vive, o que come, do que precisa, em que ambiente vive...) seja de alguma forma sobreposto pelo nicho de outra espécie, haverá competição entre elas e a intensidade desta competição depende do grau de sobreposição dos nichos. (19Ac:Br:Enc)

Em (4), "haverá competição entre elas" é uma situação pensada pelo usuário da língua como um possível resultado se acontecer o que está descrito na construção matriz, que "o nicho ecológico de uma espécie seja de alguma forma sobreposto pelo nicho de outra espécie". O emprego de "haverá" mostra claramente que se trata de algo referente ao futuro, uma vez que foi empregado no futuro do presente.

Ademais, nas ocorrências (3) e (4), mostradas acima, notamos que as construções introduzidas por "considerando que" são responsáveis por criar espaços mentais hipotéticos, ou seja, são elas que projetam o espaço mental hipotético da apódose. Assim, as apódoses não podem ser consideradas verdadeiras, mas são apenas suposições da mente humana, elaboradas para configurar o sentido condicional. Tal característica não é vista nas ocorrências (1) e (2), o que atesta que a construção "considerando que" ainda não funcionava como conectivo condicional.

\footnotetext{
${ }^{10}$ Referente ao parâmetro postura epistêmica, de Dancygier (1998).
} 
No tocante à causalidade, vemos que "considerando que" consegue ser interpretado nos quatro domínios cognitivos propostos por Sweetser e Dancygier (2005). Na ocorrência (4), temos um exemplo do domínio de conteúdo, o tipo mais básico da condicionalidade, conforme Oliveira e Hirata-Vale (2017). Em (4), a prótase "considerando que o nicho ecológico de uma espécie" seria a causa do enunciado na apódose, "competição entre elas". Ou seja, a realização da informação da prótase causaria a realização da informação da apódose. Assim, observa-se uma forte relação de causalidade entre os eventos de p e q.

Embora o domínio de conteúdo seja o mais frequente na interpretação das construções com “considerando que”, também está presente o domínio epistêmico. Nesse, a apódose funciona como uma conclusão elaborada a partir da prótase.

(5) Renan Schmidt, DJ, produtor e webdesigner: Considerando que cada vez mais casas têm um computador - tecnologia de alta performance cada vez mais acessível para a classe média - e os meios virtuais de produção musical (softsynths, samplers virtuais, seqüenciadores, etc) estão cada vez mais evoluídos, porque a produção musical eletrônica ainda engatinha no Brasil? (19Or:Br:Intrv:Web)

Na ocorrência (5), podemos fazer a seguinte leitura: "considerando que cada vez mais casas têm um computador (então) porque a produção musical eletrônica ainda engatinha no Brasil?”. O usuário da língua usa a prótase como base para poder concluir o que dirá na apódose. Ainda é possível visualizar um sentido de causa entre p e q, embora mais fraco do que no domínio de conteúdo.

Caminhando para domínios mais abstratos, nos dados coletados "considerando que" se mostrou pouco frequente nos domínios de ato de fala e metatextual, os quais não estabelecem relação de causa tão aparente, uma vez que dependem mais do contexto para seu entendimento, como mostram as ocorrências (6) e (7), a seguir:

(6) Considerando que um silo auto pode custar $\mathbf{5 0 0 . 0 0 0}$ contos, o polivalente desportivo outro tanto, tal como o recinto de feiras e exposições, sendo do campo da ficção financeira o custo dos restantes equipamentos, como pensa o Sr. Candidato pagar tudo isso, continando a pagar a VICEG, o complexo das piscinas municipais, o salário dos funcionários da Câmara e dos autarcas (incluindo o seu) e as restantes promessas que irá certamente fazer durante a campanha eleitoral (19N:Pt:Beira) 
(7) As ambiguidades estimadas absorverão parte dos erros, devido aos erros do satélite e do receptor, considerando que tais erros sejam constantes. (19Ac:Br:Lac:Thes)

Em (6), observamos que o ato de fala dito na apódose, "como pensa o Sr. Candidato pagar tudo isso" é elaborado após a informação da prótase "considerando que um silo auto pode custar 500.000 contos, o polivalente desportivo outro tanto, tal como o recinto de feiras e exposições, sendo do campo da ficção financeira o custo dos restantes equipamentos". Não parece haver relação de dependência entre p e q, mas o usuário da língua considerou relevante a enunciação do conteúdo da prótase para seu discurso. Há certa polidez em relação ao discurso, pois o usuário da língua não quer se mostrar tão invasivo e utiliza uma estratégia, a prótase, para amenizar isso. Temos, então, uma condicional de ato de fala.

Já em (7), temos um exemplo de metatextual, o domínio mais abstrato de todos, já que ao ler "considerando que tais erros sejam constantes" não conseguimos identificar de quais erros se tratam. Tal fato acontece, pois, a construção introduzida por "considerando que" funciona como retomada de algo já dito anteriormente, que, nesse caso, "tais erros" são "erros do satélite e do receptor", como consta na apódose.

Assim, nas 11 ocorrências coletadas nos séculos XIX e XX, vemos que há relação de causalidade entre as construções ligadas por "considerando que”. Então, podemos dizer que "considerando que" atua como conectivo, mais especificamente, como conectivo condicional, assumindo um significado mais procedural.

Diante da discussão até aqui proposta, vemos que a microconstrução "considerando que" enquanto conectivo condicional passa a atuar diferentemente de seu uso como verbo cognitivo, conforme ocorrência a seguir:

(8) Uma de elas envolve dois juízes: Dr Neri: pago a o dr Franklin indeferimento a o pedido de prisão preventiva 25.000,00. A sindicância está considerando que o dr. Franklin é o juiz titular de a $21^{\text {a }}$ Vara Criminal, Frankklin Belfort Neto. (19N:Br:Folha)

Em (8), percebemos um uso diferente do significado procedural que emergiu no século XIX ("considerando que" enquanto conectivo condicional). Em (8), vemos que há um sujeito gramatical, "a sindicância" que concorda com "está considerando", fato que não ocorre com o uso condicional de "considerando que", analisados acima. Ademais, percebemos em (8) uma flexão verbal, "está considerando", o que também não ocorre em "considerando que" com significado condicional, uma vez que assume forma fixa, ligando sua forma no gerúndio ao 
complementizador "que". Por fim, o verbo "considerar", em "considerando que", perde suas propriedades verbais, e passa a apresentar, a partir do século XIX, em sua forma gerúndio + o complementizador "que", também o valor de conectivo condicional, além de ser uma flexão de seu verbo cognitivo, como o da ocorrência em (8).

Portanto, defendemos que há um processo de construcionalização gramatical, isto é, há o surgimento de um novo pareamento de forma e significado na rede dos conectivos condicionais, mais especificamente, "considerando que" passa a ser mais uma microconstrução do subesquema condicional [V_que]. Esse subesquema, conforme Oliveira (2019), já sancionava a microconstrução "supondo que". Acreditamos, então, que "considerando que" foi atraído para o subesquema [V_que] por analogia ao seu membro mais frequente (BYBEE, 2010), "supondo que"11 e também passou por todo o processo de construcionalização, como "supondo que”. Em outras palavras, ocorre neoanálise, no qual os traços semânticos de “considerar” são reinterpretados, via extensão metafórica, para funcionar com significado condicional.

Com o processo de mudança, notamos que a microconstrução "considerando que" perde sua composicionalidade, normal no decorrer do processo de construcionalização. Embora seja composta pelo verbo "considerando" + complementizador "que", não é a simples soma de suas partes que faz com que ela funcione como conectivo condicional. Há fatores pragmáticos e morfossintáticos que, em conjunto, estabelecem sua função condicional.

Mesmo como microconstrução do subesquema [V_que] condicional, ainda é possível encontrar "considerando que", mas não como um chunk, como integrante da rede dos verbos cognitivos. Porém, quando considerado verbo, temos "considerando" separadamente da conjunção "que", enquanto como conectivo condicional, observamos "considerando que" como um chunk, que possui significado condicional, conforme propomos a seguir:

[[considerando_que [oração finita] $] \leftrightarrow$ [condição] $]^{12}$

Tal fato evidencia o conceito básico da teoria da mudança linguística da abordagem construcional: a gradualidade da língua, isto é, sua organização em redes de construções interligadas e o grau de pertencimento dos membros em relação às redes.

\footnotetext{
11 "Supor" e "considerar" são verbos cognitivos, com natureza hipotética.

12 “[considerando_que [oração finita]]” é a forma; “condição" é seu significado; e a seta (↔), o pareamento dos dois.
} 


\section{Considerações finais}

Ao analisar os parâmetros da condicionalidade de Dancygier (1998), confirmamos que essa integra a rede construcional dos conectivos condicionais e ainda, notamos que a microconstrução "considerando que" é mais próxima do núcleo condicional, uma vez que necessita recorrer ao contexto raras vezes para estabelecer a os traços condicionais, sendo seu comportamento bem parecido com o prototípico "se".

Com a análise diacrônica e com a teoria construcional aqui assumida, podemos dizer que a microconstrução "considerando que" sofreu micropassos de mudanças que levaram a sua construcionalização. Consoante à teoria de Traugott e Trousdale (2013), houve perda na composicionalidade da construção que passou pelo processo de mudança.

Embora não tenha sido este o objetivo desse trabalho, podemos ainda acrescentar uma descrição construcional do conectivo "considerando que": esse se encontra no nível esquemático de microconstrução, sendo uma construção menos composicional e pouco produtiva para o contexto condicional.

Contudo, as contribuições desse trabalho não se restringem apenas aos estudos da categoria condicional. Esperamos também que esse trabalho possa contribuir para o entendimento da língua enquanto um sistema de redes interligadas que se reconfiguram constantemente, devido à emergência de construções, como o conectivo "considerando que" aqui analisado, ou às construções que caem em desuso.

\section{Referências}

BYBEE, J. Language, usage and cognition. Cambridge: Cambridge University Press, 2010.

CROFT, W. Radical construction grammar. Oxford: Oxford University Press, 2001.

DANCYGIER, B. Conditionals and predication. Cambridge: Cambridge University Press, 1998.

DANCYGIER, B.; SWEETSER, E. Mental spaces in grammar: conditional constructions. Cambridge: Cambridge University Press, 2005.

DAVIES, M.; FERREIRA, M. Corpus do Português. 2006. Disponível em: http://www.corpusdoportugues.org. Acesso em: 11 jun. 2020.

NEVES, M. H. M. Gramática de usos do português. São Paulo: Editora Unesp, 2000.

OLIVEIRA, T. P.; HIRATA-VALE, F. B. M.; SILVA, C. F. Construções insubordinadas no português do Brasil: completivas e condicionais em análise. Revista Odisséia, v. 2, p. 25, 2017. 
OLIVEIRA, T. P. A construção [[supondo_que]CON. Estudos Linguísticos; São Paulo, v. 48, n. 1, p. 370-83, 2019a.

OLIVEIRA, T. P. A construção condicional em português. Revista de Letras, v. 2, n. 38, 2019b.

ROSÁRIO, I. C.; OLIVEIRA, M. R. Funcionalismo e abordagem construcional da gramática. Alfa, São Paulo, v. 60, n. 2, p. 233-59, 2016.

TRAUGOTT, E. C.; TROUSDALE, G. Constructionalization and Construcional Change. Oxford: Oxford University Press, 2013.

\section{Sobre os autores}

Duílio Fabbri Júnior (Orcid iD: http://orcid.org/0000-0002-9408-7754)

Doutor em Linguística pela Universidade Federal de São Carlos (UFSCar), com estágio sanduíche na Université de Toulouse II; mestre em Comunicação e Mercado pela Faculdade Cásper Líbero (FCL); graduado em Jornalismo pela Pontifícia Universidade Católica de Campinas (PUC-Campinas). É professor no Centro Universitário Salesiano de São Paulo (UNISAL).

Camila Gabriele da Cruz Clemente (Orcid iD: http://orcid.org/0000-0003-0709-6888) Doutoranda em Estudos Linguísticos na Universidade Federal de São Carlos (UFSCar); mestra em Letras pela Universidade Federal do Mato Grosso do Sul (UFMS); licenciada em Letras Português/Inglês pela mesma instituição.

Recebido em agosto de 2020.

Aprovado em outubro de 2020. 